\title{
College Library Exhibits: An Investigation and Report
}

For an earlier paper on college library exhibits, see the December 1943 issue of College and Research Libraries.

A REVIEw of the literature of exhibits yields comparatively little information on the nature of college library exhibits and their place in the educational program. An attempt at anything more than a surface study of current exhibit policy and practice must depend upon data drawn from other than printed sources. For this reason, the present approach to the problem is based upon material contributed by a group of college librarians in answer to a questionnaire. The utilization of a questionnaire seems to be justified since only 2 of 731 exhibits are indicated as having been publicized in general library periodicals.

The list of institutions to receive copies of the questionnaire was limited to $\mathrm{I} 2 \mathrm{O}$ liberal arts colleges. All of the colleges are accredited by the Association of American Universities and the library of each contains a minimum of thirty-five thousand volumes. The academic standing of the college and the adequacy, so far as size is a factor in evaluation, are therefore presupposed.

One hundred and one of the 120 college librarians to whom a preliminary letter was addressed agreed to make available information without which the investigation could never have been undertaken. It is regrettable that this study must confine itself largely to a report of general findings, as contrasted with descriptions of specific exhibits. The limited number of exhibits mentioned, however, speak for others of similar interest and excellence reported from various college libraries throughout the country.

Fifty questionnaires were returned with the data complete enough to be tabulated, while others were returned unanswered or incomplete, accompanied in a majority of cases by letters giving reasons for not answering. Generally speaking, figures and percentages quoted below are based on 731 exhibits from fifty libraries. In the interpretations which are made and the conclusions which are drawn, consideration is given to letters as well as to questionnaires, since they often disclose reasons for variation in exhibit policy and practice not readily discernible from the questionnaires alone.

The questionnaire was planned to cover exhibits shown within a period of a year and a half beginning Sept. I, 194I, and ending Mar. I, 1943. That this period has its irregularities can scarcely be disputed and throughout the exhibit programs studied they are reflected. Any analysis of the exhibits shown should therefore recognize the facts that for approximately fifteen of the eighteen months covered by the questionnaire the country has been engaged in a war and that college library exhibit programs, as well as other aspects 
of college library service, will necessarily show the effects of that war.

Since a review of exhibit literature brings to light no universally accepted distinction between "exhibit" and "display," the term "exhibit" has been defined broadly in order that material relevant to the study might not be lost through too rigid a definition. A quotation from a letter sent with the questionnaire shows the interpretation placed upon "exhibit:"

The enclosed questionnaire is directed primarily toward those college library exhibits which have gone a step beyond the comparatively simple display of rapidly changing composition designed to promote immediate circulation of a particular group of books. It is aimed, rather, at those exhibits of a more permanent character which, to be effective, must be preserved as a whole during the period of exhibition, which are usually located in cases in the main corridor or lobby or in a special exhibit room, which usually require some little time and thought in preparation, and which are shown at least a week and often for a month or more.

The questionnaire was devised to cover the essential features of exhibiting-subjects, materials, and purposes-and was arranged so as to interrelate the three for each exhibit reported. Sections were devoted to facilities available for exhibiting and to reasons for a definite placement of responsibility in administering the exhibit program. An attempt was also made to discover the prevailing practices in regard to amount of preparation time, length of exhibition period, and extent and type of publicity afforded exhibits.

\section{Exhibit Subjects}

From an analysis of the exhibits reported it appears that the subjects of college library exhibits do not readily conform to an inflexible scheme of classifica-

tion. These subjects differ widely and, occasionally, may be placed with equal appropriateness in two or more categories, as may "Music in Art" and "French Art and Architecture." There are also exhibits with no subjects, in the strictest sense of that term, such as a miscellaneous assortment of gifts from Friends of the Library or a varied collection of books assembled for Book Week. To avoid as often as possible arbitrary decisions in the grouping of exhibit subjects, the classification adopted is a broad one. Subjects which appear most frequently are:

\section{Subject}

Per cent of total exhibits

Description and travel

Current events (including the war, armed forces, etc.) I3 Art

English and American literature



12

Book arts

College materials

Form of materials displayed

The term "Description and travel" seems to embrace more adequately than any other, the exhibits dealing with a specific locality and covering, in a relatively large number of cases, history and geography, art and literature, social life and customs. The United States and the countries of Central and South America prove the most popular exhibit subjects. Local, state, and regional materials are emphasized in exhibits on various sections of the United States, which are typified by "Scenic New England," "The Deep South," and "Discovering East Tennessee." Central and South American countries are usually treated as a unit, and the exhibits are composed of a variety of materials, including books and periodicals, curios, costumes, and products.

Exhibits on current affairs emphasize 
national defense and the present war. Consumer problems and civilian defense, general war information, national affairs, and international relations are the broader subjects about which exhibits are centered. More specific subjects, pertinent because of their bearing on this world war, include earlier wars of the United States, democracy, propaganda, geography and war, and postwar planning. It is worth noting that in a number of instances the present policy is to convert the library exhibit program into a direct effort to aid in the war. A librarian from the Pacific Coast area writes: "For the past two years the underlying purpose of our exhibits has been to stimulate an interest in the war by showing books and pictures of the war zones and exhibiting books and pamphlets on the aims of war and peace." From the Middle West comes this report: "We try to stress particularly at this time pamphlets and bulletins relating to the war, the armed forces, and various topics of current interest." The librarian responsible for exhibits in an Eastern college strikes a similar note: "At present we emphasize materials which have a direct bearing on the war and which encourage a better morale."

The majority of art exhibits are composed of paintings, prints, lithographs, or similar materials which are shown either to promote an interest in the field of art or for their cultural effect. Other exhibits in this group are intended to instruct in some artistic process, such as "Silk Screen as a Fine Arts Medium" and "The Technique of Finger Painting." Even art exhibits show the influence of the war. Examples are "Art from Fighting China" and "Know and Defend America."

The high ranking of English and American literature as an exhibit subject can be attributed primarily to the number of exhibitions of works of individual authors. The range of subjects is from William Blake to Ted Malone, with the names of Dickens, Ruskin, and Shakespeare appearing more frequently than any others. The number of exhibits of this type which a library shows depends to some extent upon two factors. In the first place, the appearance on the literary calendar of a date such as the one hundredth anniversary of Poe's Murders in the Rue Morgue, or the centenary of the birth of William James, suggests a library exhibit. In the case of a contemporary writer, a visit to the college campus affords an excellent opportunity to display his works. The strength of the book collection in English and American literature is a second factor which may govern the number of such exhibits in a college library. If a library has no materials of unusual interest on Poe or the detective story, or no early or limited editions of William James, it is likely that Poe and James, as exhibit subjects, will be left to other libraries where these particular resources are richer and more extensive.

\section{Book Arts}

Figures show that the college library encourages in students and members of the faculty an appreciation for book design and workmanship. An exhibit may emphasize printing, binding, bookplates, or book illustration, or these features may be combined in an exhibit of the book arts in general. The account of an unusually interesting and well-planned exhibit comes from the library of an Eastern college. As a substitute for the "Fifty Books of the Year," the library prepared its own exhibit to show the features of a good book. The books were chosen in con- 
sultation with faculty members, and the labels were carefully written to emphasize the points illustrated by specific volumes. More general comments covered, among other things, the improvements in modern bookmaking and the factors which contribute to the making of a good book, including paper, typography, binding, and design.

Occasionally the growth and development of major departments, publications, and organizations within the college serve as subjects of exhibits relating to the college itself. More frequently alumni day or a college anniversary is observed by an exhibition featuring college history and the work of alumni and members of the faculty. Two of the most extensive exhibits in this group were shown in the libraries of Muhlenberg College and the Woman's College of the University of North Carolina. The librarian of Muhlenberg College writes:

In the spring of 1942 the librarian served as chairman of a committee to collect and assemble for display in the library relics associated with the Muhlenberg family, in connection with the Muhlenberg bicentennial celebration at the college. Material was borrowed from libraries, museums, churches, and individuals throughout the Eastern United States. Most of the material was from the colonial period.... The exhibit had great significance as Pennsylvania-German material. It likewise served to acquaint the college community with some of its historical and cultural background. It was visited by several thousand visitors in addition to members of the college community.

The exhibition in the Woman's College library was assembled at the time of the fiftieth anniversary celebration of the college. In addition to exhibits of college historical materials and publications of members of the faculty, books and pamph- lets from the woman's collection, gifts to the library, and the holograph collection of manuscript music by North Carolina composers were displayed.

Exhibits in which items are linked by form rather than by subject are generally intended to publicize rare or little-known contents of the library or, as in a display of gifts, to honor library donors. The materials may share some such common quality as rarity or recency. Exhibits typical of this group include: a selection of bibliographies newly acquired by the library; "Periodicals Yesterday and Today ;" an exhibit to acquaint freshmen with rare books in the library; and autographs of persons famous in history, literature, and science.

\section{Materials and Methods of Exhibiting}

Responsibility for the exhibit program. In eleven colleges the librarian is directly responsible for exhibits, while in five others it is a cooperative project between the librarian and a member of the staff. In most libraries where this is the case, the librarian plans and supervises the program as a whole, with the second person carrying out the actual preparation involved. The head of the reference department supervises exhibit work in five libraries. In five other institutions this responsibility is delegated to the associate or assistant librarian, who may also hold another position on the staff.

Exhibits in the remaining libraries are prepared by various staff members. They may be assigned to the head of the catalog department or to a circulation or catalog assistant; to the art librarian or to the readers' adviser. One college library supplements its exhibit program by exhibits prepared by students in the library school connected with the college. A second col- 
lege library reports the following policy:

At present a member of the faculty library committee has charge of the exhibits in the case. She has asked the head of each department to be responsible for a one week's exhibit. So far the plan has been quite successful in stimulating the interest of most of the faculty and indirectly the interests of the students.

In another institution exhibit responsibility rests with an exhibits committee of which the librarian is chairman, serving with the president of the college, two trustees, the head of the art department, and the chairman of the committee for outside speakers.

\section{Division of Responsibility}

Nine libraries report without comment a division of responsibility for exhibits. Such a division may be indicative of a lack of settled policy in administering the exhibit program. On the other hand, it may be explained by the fact that exhibit responsibility is rotated, as it is in a Middle Western library, where the librarian plans the first and last exhibits for the school year of ten months, with other staff members planning one each according to their various fields of interest. Student assistants are entirely responsible for the planning of exhibits in comparatively few instances, although a number of librarians suggest that the interests and abilities of capable students can be used successfully in exhibiting if their work is carefully supervised by a member of the professional staff.

Although the librarian more often directs the library exhibit program than does any other member of the staff, this condition does not imply that the duties of exhibitor automatically go with the librarianship. Instead, the delegation of responsibility is governed, in a majority of cases, by such factors as interest, training, and, less frequently, a relationship between exhibiting and other duties. Special interests for exhibitors may lie in the field of art or in early, first, and rare editions. Training may include previous experience in an art library or special art courses, a course in library publicity, or advanced work in the history of books and historical manuscripts. Duties related to exhibiting may.be in the circulation or reference departments. Other reasons appearing for the assignment of responsibility to a particular person are length of service, availability, and "sheer chance."

Facilities for exhibiting. More than one librarian not in a position to cooperate in the investigation because exhibit work was outside the scope of his program mentions a lack of exhibit space. One writes: "Our reading room is greatly overcrowded and I have no room either for exhibit cases on the floor or for anything on the walls." From another comes this statement: "C_Library is one of the many that is too crowded for exhibit cases, and we have had no experience with exhibits and unfortunately no facilities for having them." A third librarian reports his inability to answer the questionnaire: "The reason is simply that we lack space facilities for exhibits."

In addition to the amount of floor and wall space which a library may be able to devote to exhibits, the equipment available may also influence the extent and character of the exhibit program. The wide variation in the exhibit policies reported is partially explained by the fact that one library fills one table or a bulletin board for an exhibit, while another finds it necessary to fill a dozen cases. Four libraries report that they have no exhibit cases; another reports as many as thirteen. The 
median number of cases for the fortynine libraries giving this information is two.

As an exhibit program can be curtailed by inadequate facilities for exhibiting, it can also owe its extensiveness to a more generous amount of space and equipment. A special exhibit room in the library, which may be an art gallery, a treasure room, or a museum, tends to add to the relative importance of exhibits in the library's scheme of service. The reference librarian in one institution reports the following use for the library exhibit room:

One of our major purposes has been service to the local community. This being the best room in the county for art exhibits we lend it freely, thus creating local good will and bringing into the library many persons who would not ordinarily visit it.

A second librarian writes that materials are often displayed in the library exhibit cases for departments of the college and for student groups, because they will be seen by more people in the library than anywhere else. This is considered a part of the library's service to the college.

Exhibit materials. In the preparation of the questionnaire, thirty-six items which might possibly be used in college library exhibits were listed. Their variation was such as to make for categories as obvious as books and pictures and as unexpected as puppets and playing cards. The result was that every item on the list was checked at least one time. Illustrated books and pictures are each reported as shown in slightly more than one half of the exhibits, while less than one half of the exhibits contain nonillustrated textual materials. Periodicals, posters, maps, and manuscripts follow in the order named. Approximately 20 per cent of the exhibits include no books or periodicals.
From the materials used in exhibits, it is apparent that the average college library might have considerable difficulty in assembling the items from library resources. A number of exhibits must necessarily be obtained wholly or partially from commercial sources or borrowed from individuals or from groups. Twelve libraries report all materials used as available within the library. Approximately 30 per cent of the total number of exhibits include rented or borrowed items secured for the most part from individuals not directly associated with the college, from faculty and staff members, and from art associations and museums. It is evident in some instances that the number of borrowed exhibits which a library shows is greater if the library is located near other institutions which may be drawn upon for exhibit materials.

Preparation time. No discussion of college library exhibits would be complete without some mention of the time spent in their preparation. If an exhibit is planned, assembled, and arranged, all within an hour, it may be open to criticism on the ground that it has been too thoughtlessly and superficially brought together to be of any real value. On the other hand, if the preparation of an exhibit requires an exceptionally large amount of time and thought, the question may be in order: Do the results of the exhibit justify the amount of time invested in it?

College librarians were asked to estimate the number of hours spent in the preparation of each exhibit described. In a majority of cases the figures are approximate, as few library records carry this information. In addition, some difference of opinion exists as to what actually constitutes preparation time. Does it include preliminary planning, as well as 
assembling and arranging items in the exhibition? Is the time spent by a student assistant or janitor included? Since various interpretations are placed upon "Number of hours to prepare," figures are little more than general indications of the relative importance of the college library exhibit in college library service.

In approximately 50 per cent of the exhibits the actual preparation is reported as requiring from one to three hours, with close to one half of these taking from one and $a$ half to two hours. The largest amount of time was spent on exhibits prepared for college anniversary celebrations. The number of hours for one is indicated as "one hundred at least," and about another there was reported: "It is impossible to estimate the number of hours spent as preparation for the exhibit was carried on throughout the entire year and many people aided in this activity." In exhibits offered for a second time a decrease in preparation time is noticeable, suggesting a record of previous exhibits.

Exhibition time. Even though one college librarian, in commenting upon the length of time exhibits are shown in his library, writes: "Once an exhibit is set up, it is apt to stay there forever," figures show that the majority of exhibits are assembled for a period of two weeks or less. They are shown most frequently for two weeks, one week, and one month. The shortest length of time for which an exhibit is prepared is one class period. The longest time for which an exhibit is reported shown is 360 days, with no indication that the exhibit was intended as a permanent one.

Few of the reporting libraries assemble all exhibits for equal periods of time. Generally speaking, the length of time an exhibit is held in most libraries appears to be influenced by factors such as these: the purpose of the exhibit, the amount of interest shown by the students, and the amount of time which the staff is able to devote to the planning and arranging of new exhibits.

Publicity. In an analysis of the publicity received by college library exhibits, it should be taken into account that the adequacy of the publicity given an exhibit is determined by the purpose of the exhibit itself. If an exhibit is shown for students enrolled in one particular course, an announcement to the classes concerned will in all probability prove sufficient. If an exhibit is intended primarily to interest the alumni of the college in the library, effective publicity will come by way of the alumni publication. If an exhibit is prepared to increase the prestige of the library, and indirectly that of the college, it should be widely advertised beyond the campus.

The student newspaper, library posters, announcements to classes, and the local newspaper are used most frequently as channels of exhibit publicity. Approximately one third of the exhibits are reported as having received no publicity of any kind, while only 8 per cent were advertised through four or more mediums of publicity. Accounts of relatively few college library exhibits are published in professional literature.

The publicity given exhibits depends in some degree upon the general policy of the individual library. An exhibit held in one library may be highly publicized through a number of mediums, while in another library the same exhibit may receive very little, if any, notice. At times such a difference in policy is attributable to the avenues of publicity which are open to a library. For example, if a library 
has its own publication, accounts of all exhibits shown will probably be included there. If a college is located near a city, library exhibits may often receive publicity in other than local newspapers. If there is a radio station on the college campus, announcements of outstanding exhibits can be broadcast.

\section{Purposes of Exhibits}

It is evident, in looking back of the exhibit to the purpose which it serves, that a college library exhibit can be designed for one or more of several ends. An exhibit intended to advertise a special collection of which a library is justly proud may, through effective publicity, result in donations to that collection. A display of books to stimulate reading about Mexico may be related to the work of the history and Spanish departments. An exhibit of Milton first editions assembled for a class in English literature also serves to attract attention to book rarities in the library. Because of these and other relationships existing among the various purposes of college library exhibits, librarians were asked to indicate for each exhibit as many purposes as applied. Purposes reported for 73I college library exhibits are as follows:

Exhibits Having the Several Purposes

\section{Purposes}

Number Per cent

Publicize little-known or rare library materials

Stimulate reading for information, or recreational or cultural reading

Promote interest in a specific subject field or group of related subject fields

Observe a particular an- niversary or special occasion

Promote work of an individual teacher, promote interest in a specific course or group of related courses

Honor donors, attract donations, encourage sympathetic interest of Friends of the Library or others

Promote circulation of a particular class of books

Encourage hobbies

Undefined

Publicize research or other work of faculty

Promote work of student organizations

In analyzing this section of the questionnaire it appears that two of the purposes listed above act as means rather than as ends in themselves: the promotion of book circulation and the observation of a special occasion or particular anniversary. Exhibits planned to promote book circulation are generally directed toward a more intangible purpose-to stimulate reading or to increase interest in the subject of the exhibit. A majority of exhibits shown on special occasions or anniversaries are intended to encourage student reading and interest in a particular subject or to publicize library materials which are relevant to the occasion.

The greatest relative importance in a college library exhibit program would seem to be assigned to exhibits planned to publicize library materials, exhibits designed to encourage student reading, and exhibits intended to promote interest in certain subject fields. Of lesser general importance but of significance in that some few college library exhibit programs are directed consistently toward these ends, 
are exhibits prepared to result in material gain for the library or to add to library and college prestige and exhibits bearing directly upon courses in the college curriculum.

Publicity for library materials. Items shown in exhibits in this group often merit publicity because they are rare or because they are not widely known. Incunabula may be featured annually in the library exhibit cases because their rarity makes them worthy of frequent exhibition. Current publications of the United States government, which as yet have little claim to rarity, may be displayed in order to bring to the attention of students and members of the faculty sources of information which may prove of use to them. In over one half of the exhibits planned to publicize rare items, the materials are also checked as being little-known, indicating that library resources which are considered rare have often not been widely publicized.

\section{Rare Materials}

Picked at random from the list of items displayed because of their rarity are autographs; books, including old Bibles and hymnals, early atlases, examples of fine printing and binding; clay tablets ; periodicals, with the emphasis upon early and foreign ones; pictures; and relics. The library of one Eastern woman's college featured the works of scholarly women of the seventeenth and eighteenth centuries in an exhibit entitled "Learned Ladies." Other specific examples of this type of exhibit include: American newspapers for the period I 800 to 1863 ; sixteenth-century printers' devices and types; early issues of Godey's; cartoons of the First World War. Materials may also be considered rare because of their subject matter or association value. Chief among these are items relating to the history of the college, including files of college publications and writings of faculty members and alumni. Local, state, and regional materials fall within this category, with emphasis upon early local imprints and the literary output of local authors.

Little-known materials used in exhibits include such items as bibliographies, "Fifty Books of the Year," documents, pamphlets, postcards, and textiles. Publications on vocational guidance, and books, pamphlets, and periodicals from war information centers are exhibited because they are thought to be unfamiliar to students on the campus. One exhibit reported, featuring library resources of which college students might be unaware, was composed of books in the languages of foreign countries which are prominent in the news today, such as Russian, Japanese, Chinese, Norwegian, and even native dialects from parts of Africa.

Exhibits in this group are often planned to answer a second purpose: to promote interest in a subject field or to stimulate reading and, less frequently, to commemorate a special occasion or to promote the instructional work of the college faculty. Studying the exhibits collectively, it would seem that their educational value is strengthened if they are made to serve a dual purpose. Some question might be raised as to the time the average college student stops to consider an exhibit of this type unless it relates to his curricular or extracurricular activities. One college librarian speaks of this: "Students rarely study an exhibit carefully. One glance tells them if the subject concerns them. If it does, they may give it a second glance ; if not, they walk off."

Stimulation of student reading. The 
Ioo Great Books of St. John's College, the Rivers of America series, and the American Guides furnish materials for exhibits in this group. One college library displayed "Reliable Sources of the News," which included examples of authoritative newspapers, magazines, and pamphlets. A second institution showed pictures and writings of prominent foreign correspondents. "The Negro Writes His Own History" surveyed typical historical works of Negroes from mid-nineteenth century writings to contemporary social history.

The caption "The Mood Is Met" covered a collection of books to appeal to readers in various moods. A Southern woman's college reports a series of weekly rocational guidance exhibits dealing with such topics as "Women in Science," "Women in Medicine," "Women in War Work," "Teaching," "Librarianship," "Social Service," "Secretarial," and "Personnel." A display of books for Christmas vacation reading shown in an Eastern institution was accompanied by an annotated book list.

\section{Stimulating Student Reading}

Exhibits of books assembled for the purpose of increasing student reading occupy a primary place in the exhibit programs of a number of the libraries canvassed. Two quotations from college librarians serve as evidence. The first librarian writes: "Our purpose is almost entirely directed toward leading college students to do some reading in addition to that required in their courses." And from the other comes the following statement: "[The publicity program] is designed primarily to stimulate use of books by the students, to make easily available groups of books of timely interest, to keep all users of the library informed of new acquisitions, and to bring to the student's attention fields of knowledge which possibly receive little emphasis in his course of study." Such opinions when checked with the subjects of the exhibits in this group indicate that the reading which is encouraged is largely of an extracurricular nature.

On the other hand, several college libraries report very few, if any, exhibits planned to stimulate student reading. The indication is that this purpose is met by temporary displays which supplement the more formal exhibitions.

Promotion of interest in a subject field or group of subject fields. Barring the fields of art and literature which are discussed above, no more than 3 per cent of the exhibits are reported as lying in any one specific academic field. Further along in the listing of exhibit subjects these fields begin to appear: religion, with the number of exhibits increased by displays of Bibles and religious relics; drama; the Greek and Latin classics; science, with a scattering of exhibits through chemistry, biology, botany, and mathematics; education; geography, with the emphasis upon maps and atlases; music; home economics, brought into the picture by an increased number of exhibits dealing with nutrition; architecture; and physical education.

In a considerable number of instances it appears that the term "subject field" as used in connection with exhibiting is not synonymous with "academic subject field." The word "subject" in exhibit practice is more nearly analogous to its meaning in the term "subject heading" as used by a cataloger, referring to such topics as vitamins, children's books, victory gardens, and Latin America. Of the 205 exhibits prepared to promote interest in a specific subject field or group of related 
subject fields, ninety-nine are also designed to stimulate reading which is largely of an extracurricular nature. This fact, coupled with the interpretation placed upon "subject field" in a relatively large number of libraries to which the questionnaire was sent, would seem to indicate that exhibits in this group are not as closely related to the program of instruction as might at first be supposed.

Advancement of the instructional program. The following quotation comes from Dr. Branscomb's Teaching with Books:

In visiting the libraries one sees many exhibits of books for recreational reading, current fiction, biographies, travel books, and the like. One often sees displays of new books of general interest. I have yet to see an exhibit of books of interest to students in connection with any course of study. The reply that the course readings set up by the faculty constitute the exhibits in these cases is not quite adequate in view of the possibilities of added attractiveness and interest which a capable and interested librarian would often see in such shelves. ${ }^{1}$

Dr. Branscomb's words are three years old, and today close to 17 per cent of the exhibits described by college librarians fall into the group which can be designated as curricular. For the most part, however, these exhibits are found in the libraries of a limited number of colleges and are concentrated in a few academic subject fields.

Among the libraries directing at least a part of their exhibit programs along curricular lines are the libraries of Wellesley College and Middlebury College. Teaching exhibitions at Wellesley College cover a number of the major subject fields, including the classics, mathematics, and his-

\footnotetext{
1 Branscomb. Harvie. Teaching with Books: $A$
Study of College Libraries. Chicago, Association of American Colleges and American Library Association, 1940, p. 83-84.
}

tory, but emphasis is primarily in the field of English literature, owing to the library's special collection of English poetry. The exhibits, which are composed almost entirely of rare items, are arranged by the curator of rare books, who talks to classes about the materials displayed. Rare items, through exhibition, are related to student work and interests and are made to contribute significantly to college education.

Cooperation with the teaching faculty is evident in the exhibit program of Middlebury College. Curricular exhibits are described in the Bulletin of the library: "Each week throughout the winter we hope to have exhibits sponsored by members of the faculty, bringing to the attention of the students noteworthy phases in the work of all departments ;"2 and later: "In the main reading room there have been exhibits staged by different departments of the college, displaying everything from the extraction of rubber from goldenrod to facsimile coins of the days of Julius Caesar."3 The psychology department was represented by an exhibit on "Mental Testing;" mathematics by an exhibit featuring an old calculating machine; and home economics by materials on food rationing and the history of costume.

That certain other libraries may be studying their exhibit programs with a view toward integrating them more closely with the actual instruction of the college is suggested by a statement from the librarian of a Middle Western college :

In my judgment we have not yet worked out a well-integrated plan for exhibits which would relate to and reinforce the courses offered in the curriculum. It has been my hope that the various members of

2 Middlebury College Library, Middlebury, Vt. Bulletin, v. 10, no. 2, October 1942, p. [1]. Mimeo-

graphed. 
the faculty might be aroused to a greater interest in the possibilities. We have ample illustrative material in the library for the purpose, even though a good deal of it is not original source material.

Encouragement of interest in the library on the part of persons not directly associated with the college. In regard to the contribution which an exhibit can make toward increasing library and college prestige and toward securing the interest of valuable friends, a description of exhibits shown in the Wesleyan University Library before the war is pertinent:

During the last eight years we have had several exhibits of more than usual importance. One, "First Appearances of Familiar Quotations," one on Robert Frost, and one on Gilbert and Sullivan. For each of these we were fortunate in securing exceptionally important private collections and the cooperation of the owner of these collections in their display. For each of these exhibits we published a catalog in bound book form. These books we attempted to do rather nicely, printed them in limited editions, and each one promptly became a "collector's item" in its own right. Each of these exhibits received rather wide publicity, including feature stories in the New York Times Book Supplement and similar publications. The war put a temporary quietus on this sort of exhibit. In the case of our more important exhibits we have tried to "open" them with teas or lectures by some authority in the field covered or with some other special send-off.

For the library unable to hold exhibitions as extensive as those described above, simpler exhibits carefully planned and wisely publicized may in a smaller way obtain similar results. One college library reports the exhibition of a collection of historical documents of the college timed for a meeting of the state historical society on the campus.

Exhibits may also be shown to honor past donors or, as already indicated, to draw other donations. Miscellaneous collections of gift books acquired during the college year are exhibited as a courtesy to the donors. Individual donors are honored through exhibits if their gifts are sufficiently noteworthy to deserve exhibition. The library of one woman's college reports an exhibit of books and manuscripts from a special collection gathered and financed by the alumnæ association of the college. Rarest items were featured and the most important funds and donors were represented.

An exhibit to honor donors may serve to attract additional gifts if it receives thoughtful planning and proper publicity. With the exception of books collected in the Victory Book Campaign, exhibits designed to attract donations are usually composed of items, often rare, which represent a special interest in the library: alumni writings and college memorabilia, fine printing from private presses, letters and documents relating to the early history of the state, first editions of a particular author who may be an alumnus of the college. If the library policy is to strengthen certain collections through gifts, exhibits of these collections, if brought to the attention of the proper audience, may exert a favorable influence upon prospective donors.

\section{Conclusion}

Cumulative figures may well be accepted critically and deliberately, since they may at times be affected disproportionately by conditions peculiar to the individual library. One librarian writes: "It seemed to me when I came to the library that our entire student body should be made more 'art conscious," " with the result that items from the art library are 
exhibited frequently. A second librarian explains the number of exhibits of college materials shown in her library as follows: "The college is fortunate in having a well-organized and extensive college history collection. This coupled with the fact that we are one of the oldest of the women's colleges makes it seem advisable to stress the historical aspects of the college." Exhibits in the library of a Negro institution may stress the history and achievements of the Negro race, while a college library faced with the problem of student misuse of books may utilize the exhibit as one means of educating the student body to respect library materials. Factors such as these, plus the wide variation in exhibit facilities in college libraries, make one slow to judge an exhibit program adequate or inadequate or to accept total figures without some reservation. These figures serve only to point the way toward a general interpretation of current exhibit policy and practice.

By combining figures from the preceding sections of the study, various parts of the questionnaire can be made to work together to supplement and explain one another. As subjects, materials, purposes, and methods can be linked to sketch a specific exhibit, they can also be related to describe the typical college library exhibit. It is an exhibit dealing with a specific country or locality, assembled primarily for the purpose of publicizing library materials. The exhibit is composed mainly of books and pictures, supple- mented by articles borrowed from members of the faculty and from other individuals. It is shown for two weeks in two exhibit cases, and an account appears in the student newspaper. The librarian is responsible for planning the exhibit and from one and a half to two hours are spent in assembling and arranging it.

The typical college library exhibit considered in this study, with certain striking exceptions, is not used as an instrument in the integration of the library program with the instructional program. On the contrary, it is designed chiefly to show the independent resources of the library for self-cultivation and to display "unusual books, books demanded by potential leaders." 4 In such a use of exhibits the college library shares with the museum, the public library, and the university library in a program planned to serve the community of which it is a part, to give publicity to its holdings, to increase these by the stimulation of gifts, and to encourage independent reading. The college library shows an awareness of the effectiveness of these exhibits, but it need not stop with such a conception of its exhibit work. The potentialities of the college library exhibit as an implement of college instruction are not as widely recognized. The development of the curricular exhibit will call for new and vigorous plans, to be carried out jointly by the library and departments of instruction.

4 Adams, R. G. Address at the Dedication of the Stockwell Memorial Library at Albion College, June 4, 1938. Albion College, 1938 , p. 18. 